\title{
Macro-economic Determinants of Recent Inflation in Ethiopia
}

\author{
Tadesse Wudu Abate \\ Department of Economics, Faculty of Business and Economics, Woldia University, Woldia, Ethiopia
}

Email address:

tade.wudu22@gmail.com

\section{To cite this article:}

Tadesse Wudu Abate. Macro-economic Determinants of Recent Inflation in Ethiopia. Journal of World Economic Research. Vol. 9, No. 2, 2020, pp. 126-132. doi: 10.11648/j.jwer.20200902.17

Received: October 9, 2020; Accepted: October 23, 2020; Published: November 19, 2020

\begin{abstract}
Expansion is one of the major macro-economic issues which determine the better functioning of the economy. Additionally, it leads a multi-dimensional effect on the overall social, economic, financial, mechanical and political affairs of the country. To come with this problem, the study focuses on the identification and assessment of variables which determine the rate of inflation in Ethiopia using annual data from the year 1985 to 2018. The study used secondary time series data and applies econometric analysis to identify significant variables in determining inflation both in the long run and short run and descriptive methods of data analysis to identify the trend of inflation and money supply. The finding of this study shows that real interest rate and real effective exchange rate are significant in determining inflation both in the short run and long run. Broad money supply determines inflation only in the long run and gross domestic saving doesn't determine the rate of inflation both in the long run and short run. The monetary base of the country which is broad money supply has some dispersion or different impact in determining inflation. It has significant impact in the long run but became statistically insignificant in the short run since monetary policy has higher outside lag and needs longer time to affect inflation after increasing money supply. So it is advisable to the policy makers to find the right balances whether money supply permanently determines inflation rate or it is insignificance in both short run and long run models.
\end{abstract}

Keywords: Ethiopia, Inflation, Money Supply, Multiple Regression

\section{Background of the Study}

Inflation has a long history coinciding with the time of introduction of use of money as a medium of transaction. However, during and after World War II, inflation increased at alarming rate when government financed the war, or in periods when gold discovers of the valuable changes had been made [9]. The Second warfare among rapid world inflation as had often been happened often before, the war time inflation continued into post- war period. Retail price within the main industrial countries rose at a mean rate of about 2-4 percent each year from 1953 to 1959. After 1974 the rate of inflation had raised quickly in most industrialized counties. Therefore, there must be reduction of the impact of inflation on the graceful operation of the economy, essential to understand the method that makes inflation, the way during which it perpetuates itself the condition to which leads and therefore, the means by which it's managed In developing country one finds that the literature contains two major competing hypotheses which attempts to clarify the manufacturing rate of inflation [5]. First, the monetarist states that inflation is pure monetary phenomenon. On the opposite hand, the structuralists argued that causes of inflation must be sought in certain structural characteristics of developing economy, which makes them particularly inflationary pressure. In keeping with structuralists view, inflation may result from supply inelastic was down ward inflexibility of price and income an increase in developing country. Although the developing countries have faced different serious macroeconomics problems such as drought, devastating wars and distorted investment environment, the inflation within these countries were not miserable, and it had been very low in the past regime, except, the 1972/73 and 1978/79 oil crises and fluctuations of non-oil import prices. Because control has kept prices stable. Additionally the lower and pegged charge per unit has also helped to lower the impact of international price like in Ethiopia and makes imports cheaper. During the sooner years of present regime 
also inflation had been low [14]. However, in the post 2002/03, inflation became a serious problem of Ethiopia following the government's move towards less conservative monetary and financial policy, and state activism as a developmental state within the economy. During the identical period, the economy is reported to own recorded a quick growth, export receipts have increased substantially and domestic government income has increased. Government expenditure have grown considerably, there has also been fast increase in monetary resources mainly as a result of growth in fiscal deficits. Studying the linkage between price developments and various macro-economic variables will, therefore enable us to grasp the causes of the present inflation in Ethiopia [1].

Habtamu [5] conducted a study which suggested that cash supply has significant role in determining inflation in Ethiopia used the information between 1962 and 1997 but he ignored the impact of other variables like government expenditure and gross domestic saving on the inflationary pressure on Ethiopian economy. Another study by [2], analysis current inflation in Ethiopian economy using econometric model and She included CPI as variable and pecuniary resource, real GDP as an independent variable and suggests pecuniary resource wear any impact in determining inflation in Ethiopia. This study included up-to- date information on statistic variables up to a year of 2018 and real interest rate which had not been attempted by the previous works as a serious determinant of inflation in Ethiopian economy. This study also included variables such pecuniary resource, gross domestic saving, real rate of interest and real effective rate test their significance to work out inflation (in which it's percentage change within the general index.) by employing both econometric and descriptive methods of information analyzing.

\section{Review of Related Literatures}

Demand pull inflation is the traditional and most typical type of inflation [14]. This type of inflation occurs when aggregated demand of a given economy is greater that its aggregate supply. Excess demand may occur because of increase in one or all components of aggregate demand which has consumption, investment, government expenditure and net exports. The excess demand creates disequilibrium and pulls up prices until equilibrium is restored. This can be because the rise in aggregate demand causes shortage of products and services at old prices. As a result consumers, business, and government bid against each other for a set quantity of accessible goods and services. This successively results in price increases until equilibrium is restored, [6].

Classical and neoclassical economists use the amount theory of cash to elucidate the sources of inflation. In its transactions version the QTM states that "the value of all sales of products must necessarily equal the worth of all purchases" [8].

The original QTM as expressed by Fisher's equation of exchange is given as:
$\mathrm{M} . \mathrm{V}=\mathrm{P} . \mathrm{T}$ Where, $\mathrm{M}$ is pecuniary resource, $\mathrm{V}$ is velocity of cash, $\mathrm{P}$ is general indicator and $\mathrm{T}$ is real volume of transactions. The speculation is made around two assumptions: constant velocity of cash and financial condition of resources. The belief of financial condition implies that the quantity of transactions (T) is constant.

Alfred Marshall modified the number theory of cash by introducing liquidity preference into the amount equation:

$\mathrm{M}=\mathrm{k}$. (P.Y) Where $\mathrm{M}$ is cash in hand, $\mathrm{k}$ is that the fraction of income people wish to carry within the sort of money, $\mathrm{P}$ is price index and $\mathrm{Y}$ is real output. Change within the preference of holding money reflected in change in $\mathrm{k}$ may produce large and quick changes in output and costs.

The implication of Alfred Marshall's version of QTM is that inflation is explained not only on by increase in finances, but also by psychological change in liquidity preference. The classical/neoclassical theory of inflation has two essential characteristics: first, inflation may be a condition phenomenon and second, inflation might be an investment's phenomenon. These two features are reflected by the equal percentage change in price for any percentage growth within the stock of money supply [12]. This assumes unit elasticity between prices and takes advantage hand. The condition of proportionality will hold on condition that certain conditions are satisfied: the economy should always be operating at a financial condition, money demand should be stable, monetary resource must be exogenous and money must be neutral. Additionally, to those conditions, given the definition of inflation as continuous rise in price level, parameters within the economy should remain unchanged over the quantity under investigation. In a globe economy, however, most of these assumptions are unlikely to hold. Most economies, a minimum of the developing world, are operating below condition as evident within the rapid growths of rate; cash isn't purely exogenous and economic parameters exhibit temporal variation. Applying the classical/ neoclassical theory on its own to understand inflation in developing countries may not produce the total picture. (1)

During the study of inflation in Ethiopia used quarterly data from 1967/68 to 1998/99. He used three econometrics models monetarists, demand and provide side model and structuralism model. Results from the primary model show that cash supply may be a reason behind inflation within the short run [13]. The results from the second model saw that inflation inertia and actual world inflation affect Ethiopian inflation within the short run. Within the last model structural variables are found to elucidate both short run and future inflation in Ethiopia while inflation inertia, monetary resource and world inflation explain inflation only within the short run. [16]

Kibrom [6] Examines the sources of recent inflationary experience in Ethiopia between 1994/5 and 2007/8 using vector auto regressive (VAR) and single equation error correction models. He finds that the determinants of inflation differ between sectors (food and non-food) and therefore the time horizons into account. The foremost important forces behind food inflation within the future are real income, 
finances, inflation expectation and international food prices. The long term determinants of non-food inflation, on the opposite hand, are funds, rate of interest, and inflation expectation.

Taddele [15] Investigated the character of inflation in Ethiopia and constructed a model which will be wont to forecast future values. The exponential smoothing model was employed and also the forecasting performance of winter (additive) models was found to be better. Two alternative approaches for model identification were considered, namely, the Box-Jenkins methodology and Penalty function criteria. For Ethiopian monthly inflation data covering the amount 1997 to 2006 ARMA model was fitted [10].

Muche [11] Used structural vector autoregressive model (SVAR) with two variables-real output and CPI. He tried to check the effect of demand and a supply shock on real output and suggests that prime rate of inflation in Ethiopia is an outcome of demand and/or supply shocks. He argues that within the periods considered within the study inflation is especially driven by demand factors and result of this study agreed with a result of a study conducted by [3].

\section{Materials and Methods}

The model employed in this study is multiple linear regression models. Then after applying the OLS estimation technique, post estimation diagnosis tests of multi-collinerity, hetroskedasticity, autocorrelation, model specification, and normality is tested. Additionally, the co-integration test for long run and error correction model to short run had been developed to check either there is the true relationship between the dependent and the dependent variables or the regression is spurious. To identify the specific relationship between inflation and its determinants the study has to test the data set to stationary and non-stationary using augmented dickey fuller(ADF) and dickey (DF) tests. If the data has tested to be stationary, the ordinary least square (OLS) technique will be involved to identify the consistency and correlation between inflation and its determinants.

In this study inflation is specified as a function of broad money supply growth rate, real interest rate, gross domestic saving growth rate and real effective exchange rate.

$$
\mathrm{Lnf}=\mathrm{f}(\mathrm{m} 2, \text { rir, gds, reer })
$$

By introducing the constant term, the value of the dependent variable without the effect of the independent variables, the coefficients of the independent variables which shows the sign and magnitude of the effect on independent Variables on the dependent one and the error or the disturbance term which will capture the effect of variables which have impact on the dependent variable but not included in the model, the model of inflation is specified as follows:

Model Specification

$$
\operatorname{Inf}=\beta 0+\operatorname{lnm} 2+\beta 2 \text { rir }+\beta 3 \operatorname{lngds}+\beta 4 \text { reer }+ \text { Et }
$$

\section{WHERE:}

Inf $=$ rate of inflation $\ln M 2=$ broad money supply growth rate

$\operatorname{lnGDS}=$ gross domestic saving growth rate rir $=$ real interest rate

reer $=$ real effective exchange rate and $\mathrm{Et}=$ error term

Data type and sources

The study used in this study covered the time period between (1985-2018) annual report data. The necessary data important for this study are secondary time series data that are to be obtained from national bank of Ethiopia (NBE), Minister of finance and economic cooperation (MoFEC), Ethiopian economic association (EEA) and statistical central authority (CSA). Specifically, the data on gross domestic saving from MoFEC, the data on inflation rate, real interest rate, broad money supply and real effective exchange rate will be obtained from NBE.

\section{Results and Discussion}

\subsection{Descriptive Analysis}

Trends of inflation

Trend refers to the direction of movement of variables from time to time. The trend of inflation in most of lessdeveloping countries is known by its fluctuating character in the economy. Inflation in Ethiopia is characterised by the successive ups and down movements.

The inflationary trend of Ethiopia from the year 1980 to 2013 is presented in the following graph.

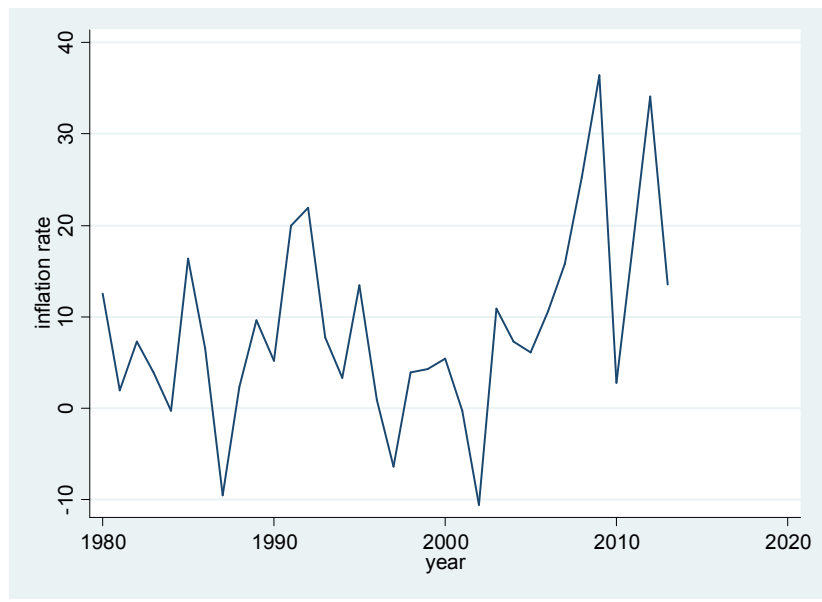

Figure 1. Trends of inflation rate.

From the above graph, we can see that, high inflation rate were occurred in Ethiopia in the last decade of twenty century specifically from the year 1994-2000. The cause for this higher magnitude on inflation was studied by many economists and it's found that, devaluation and cancelation of many policies by the transitional government after the downfall of derg regime was the man cause for higher rate on inflation in Ethiopia. During that time the government took fiscal and monetary policy measures by aiming the reduction in money supply, domestic credit and bank financing. Then finally the government was successful in restricting the 
aggregate demand of the people by taking the above instruments and this condition leads to lower rate on in the tear 2000 . The year 2008 was known by the time of higher inflation rate in all countries of the world. Ethiopia also had recorded its higher level of inflation from the year 2008 to 2010. This higher inflation was occurred due to higher rise in the price of oil which was deliberately set by oil exporting countries. The government of Ethiopia was not successful in controlling this higher rate of inflation even though it applies varies monetary and fiscal policies to control money supply growth rate.

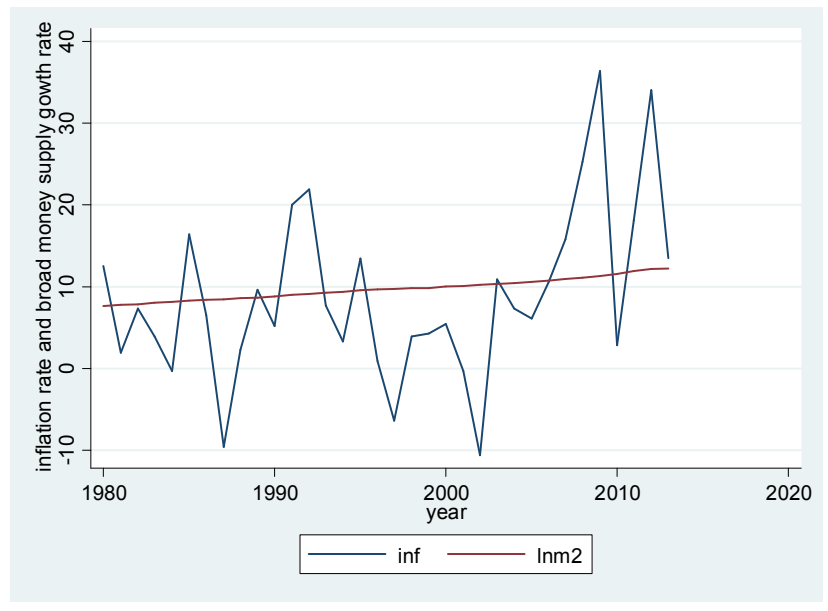

Figure 2. Trends of inflation and broad money supply.

As shown in the above graph, money supply had almost constant trend and it is less fluctuating in all the sample period. On the other hand inflation rate in plotted in the graph with extreme ups and down movement including from its lowest value in 2002 and its highest value in the year 2008. Money supply is increased from time to time but with decreasing rate and money supply is increased and decreased from time to time. So in this paper it is concluded that money supply has only little impact on the rate of inflation in Ethiopia.

Table 1. Skewness/Kurtosis tests for Distribution.

\begin{tabular}{llllll}
\hline Variable & Obs. & $\begin{array}{l}\text { Pr } \\
\text { (Skewness) }\end{array}$ & $\begin{array}{l}\text { Pr } \\
\text { (Kurtosis) }\end{array}$ & chi2(2) & Prob>chi2 \\
\hline Inf & 34 & 0.0725 & 0.2008 & 4.86 & 0.0879 \\
$\ln 2$ & 34 & 0.4829 & 0.1717 & 2.36 & 0.3073 \\
Rir & 34 & 0.2751 & 0.7556 & 1.29 & 0.5252 \\
Lngds & 34 & 0.0654 & 0.7322 & 3.51 & 0.1728 \\
Reer & 34 & 0.0930 & 0.8430 & 2.86 & 0.2392 \\
\hline
\end{tabular}

Based on the measure of symmetry as indicated by the result of skewness, the data set on any of the variable is said to be symmetrical if and only if the value of skewness is approximately zero. The data is negatively skewed when its value of skewness is less than zero and it is positively skewed when the value of the skewness is greater than zero. From the above table it is clear that all-time series variables are skewed to the right or simply they are positively skewed. Since the variables are not normally distributed, rousted regression is applied to capture the non-normality of variable on the estimation results and that is why other tests like SW are not applied here.

\subsection{Econometric Analysis}

This section deals with estimating and interpreting the main behavioural and policy variables which determine the overall rate of inflation. The time series data over variables from the year 1985 to 2018 is tested for stationary, co integration, the error correction model, multicollinearity, hetroskedasticity, auto correlation and normality of the error term.

\subsubsection{Stationary Test: Unit Root Test}

Table 2. Test for unit root.

\begin{tabular}{|c|c|c|c|c|c|c|}
\hline Variables & Test statistics At level & Test statistic at difference & $1 \%$ critical value & $5 \%$ critical value & $10 \%$ critical value & Stationary \\
\hline $\operatorname{Inf}$ & -3.899 & -7.380 & -3.696 & -2.978 & 2.620 & At level \\
\hline $\operatorname{lnm} 2$ & 2.538 & -3.095 & -3.702 & -2.980 & -2.622 & At first difference \\
\hline Rir & -3.250 & -6.395 & -3.696 & -2.978 & -2.620 & At level \\
\hline Lngds & 0.106 & -7.753 & -3.3 .702 & -2.980 & -2.622 & At first difference \\
\hline Reer & -1.750 & -5.254 & -3.702 & -2.980 & 2.622 & At first difference \\
\hline
\end{tabular}

Source: Owen computation using stata.

As we seen from the above table (table 2) variables such as inflation and real interest rate (rir) are stationary at level. Other variables including money supply, gross domestic saving and real effective exchange rate are stationary at level.

When we look at the result on ADF test with constant, trend and lags (1) conducted on the difference of variables which are not stable at level, it is found that all variables are stationary. The computed test statistic is greater than Mackinnon critical value and the null hypothesis for the existence of unit root is rejected after first difference.
All dependent and independent variables are stationary which indicates the relationship exists between inflation and its determinants are true and long run(but after tested for co integration), not only for the time period in which the sample is taken. In general, there is no spurious regression.

\subsubsection{Estimation of the Long Run Model}

The long run model for inflation based on the time series variable is estimated as follows. 
Table 3. The long run model.

\begin{tabular}{lllll}
\hline Variables & Coeff & Std.error & t-value & p>t \\
\hline $\ln 2$ & 9.206 & 3.323 & 2.77 & 0.010 \\
Rir & -0.394 & 0.1486 & -2.65 & 0.013 \\
Lngds & -4.523 & 3.12 & -1.45 & 0.157 \\
Reer & 0.101 & 0.31 & 3.29 & 0.003 \\
Cons & -58.12 & 15.065 & -3.86 & 0.001 \\
\hline
\end{tabular}

$\mathrm{R}^{2}$ (0.51), Adj.R2 (0.45), F (4,29) 7.72 (0.002), Vif (5.63), Hettest Chi.2 2.12 $(0.15)$, Ovtest F $(3,26) 2.10(0.125)$, D-w test $(5,34)=2.18$.

Source; own computation using stata.

The equation for inflation is formed as follows;

$\mathrm{Inf}=-58.12+9.02 \operatorname{lnm} 2-0.394$ rir $-4.523 \operatorname{lngds}+0.101$ reer $+\mathrm{e}_{\mathrm{t}}$

$\begin{array}{lllllll}\text { Prob5 } & 0.001 & 0.010 & 0.013 & 0.175 & 0.003 & 0.0001\end{array}$

The results of the equation estimated to verify the impacts of macro variables on the inflationary trend of Ethiopia passes various important diagnostic tests. The vif with the quantitative value of 5.63 which is less than 10 indicates that the model is free from multicolinearity problem and the test for hetroscedastisity since the probability is greater than $5 \%$ ( which is $15 \%$ ) there is constant variance.

The value of $\mathrm{R}^{2}$ measures that, out of the total change in the dependent variable which percent is determined within the model [7]. In this model the value of $\mathrm{R}^{2}$ is 0.51 it shows that out of the total change in inflation $51 \%$ is determined by the independent variables included in the model jointly. The Durban-Watson d statistics in this model is 2.18 which indicate that there is no autocorrelation problem in this model. The F- test for aver all significance and the ovtest for model specification shows that all variables are statistically significance jointly and there is no omitted variable in the model respectively.

The estimated coefficients of the long run model for inflation rate from the above estimated model reflect that three variables namely broad money supply, real interest rate and real effective exchange rate are consistence and statistically significant. Accordingly the rate of inflation is positively related with broad money supply and real effective exchange rate but negatively related with real interest rate. Among explanatory variables include in the model gross domestic saving is statistically insignificant have no impact on inflation.
The coefficient of money supply is 9.20 , meaning citrus paribus, 1 unit increment in money supply will leads to the rate inflation to rise by $9.20 \%$ on average value. This means when the amount of money in the circulation increases, everyone will hold higher amount of money on hand and not being sensitive any increased in the price of commodities but can afford at any price. Due to this effect inflation will rise due to high money supply. The coefficient of real interest rate which is -0.394 is to mean as interest rate increased by 1 unit inflation rate will be decreased by 0.394 other things remain constant and on average value. Increased interest rate means low money supply since everyone is saving his money to gain interest income. The positive coefficient of real effective exchange rate $(0.101)$ is interpreted as, if exchange rate is increased by 1 unit, then inflation rate will be increased by 0.101unit.

\subsubsection{Normality Test}

Table 4. Shapiro-Wilk W test for normal data.

\begin{tabular}{llllll}
\hline Variable & Obs & W & V & Z & Prob $>\mathbf{z}$ \\
\hline $\mathrm{R}$ & 34 & 0.96830 & 1.107 & 0.212 & 0.41611 \\
\hline
\end{tabular}

Source; own computation using stata.

According to the Shapiro-wilk W test for normality the error term is said to be normally distributed or the null hypothesis which says the error term is normally distributed is rejected when the value of sw is less that the relevant critical value.

On the other hand, the error term is said to be normally distributed if it has zero mean and constant variance [4]. In this model the swilk $r$ test shows that the mean value of the error term (probability) is zero in approximate value. Previously the model was tested for hetroscedasticity and its variance is proved to be constant. There for the error term is normally distributed.

\subsubsection{Test for Co Integration}

After testing for the stationary of variables (which are stationary at level and first difference), which is necessary condition for co integration the next step for testing the existence of long run relationship is the error correction model.

Table 5. Co-integration test.

\begin{tabular}{|c|c|c|c|c|}
\hline Variable & Test statistics & $1 \%$ critical value & $5 \%$ critical value & $10 \%$ critical value \\
\hline$E$ & -6.430 & -3.696 & -2.978 & -2.62 \\
\hline
\end{tabular}

The above table shows that the disturbance term is stationary at $1 \%$ mackinnon critical value. The null hypothesis which says there is unit root for the error term will be rejected since the calculated test statistics is greater than $1 \%$ critical value in absolute term. This means there is co integration between inflation and its determinants. So the relationships exist between inflation and other independent variables are meaning full and the regression formed is not spurious.

\subsubsection{Multicollinarity Test}

This test shows as if there is perfect correlation between the explanatory variable those incorporate in model. The existence of Multicollinearity problem detect thought the use of variance inflation factor (VIF). According to the above model the long run relationship between explanatory variable will present in table below. 
Table 6. Test for Multicolinarity.

\begin{tabular}{lllll}
\hline Variable & Inm2 & Lngds & rir & Reer \\
\hline VIF & 6.83 & 9.20 & 4.91 & 1.58 \\
1/VIF & 0.1464 & 0.1086 & 0.2036 & 0.0172 \\
Mean $V I F=$ & $\frac{\sum}{n}=\frac{D I F}{2}=\frac{2.52}{4}=5.63$ & & & \\
\hline
\end{tabular}

Own computation using Stata.

The result from the above table indicates the VIF is less than 10 for any of the explanatory Variables, i.e from the result the Mean VIF is 5.63. And hence from the result the mean vif is less than 10 so there is no Multicollinearity problem.

\subsubsection{The Short Run Model}

The short run model which helps to identify the relevant and significance variables in determining the inflation rate in the short run is specified as follows.

Table 7. Results for error correction model.

\begin{tabular}{llllll}
\hline Inf1 & Coef. & Std. Err. & T & P>|t| & [95\% Conf. Interval] \\
\hline Reer1 & .0835006 & .042929 & 1.95 & 0.064 & -.0051005 .1721018 \\
Lnm2 & 28.78 & 42.97 & 0.67 & 0.569 & -2.450 .82 \\
Lngds1 & -2.69256 & 2.572645 & -1.05 & 0.306 & -8.0022372 .617118 \\
Rir1 & -.6270041 & .1829093 & -3.43 & 0.002 & $-1.00451-.2494978$ \\
lag1 & -1.783067 & .3208718 & -5.56 & 0.000 & $-2.445314-1.12082$ \\
cons & -.0044222 & 1.298224 & -0.00 & 0.997 & -2.6838242 .67498 \\
\hline
\end{tabular}

$\mathrm{R}^{2}=0.22$, Ovtest $=\mathrm{F}(3,24)=0.28(0.8422)$, Dw stat $=1.96$, Vif $=1.32$ Hettest $=\mathrm{F}(3,24)=0.28(0.8422)$.

Source: own computation using stata.

The model has been tested for hetroscedasticity, multicollinearity, autocorrelation and whether the model has omitted relevant variables at the time of specification. Accordingly, the model has no problem of these tests. The DW test for autocorrelation is 1.96 showing the absence of this problem since its value (1.96) approaches to 2 . The value of vif is 1.32 which is less than ten, tells as there is no multicolinearity problem. The other test done in this model which is the ov test, valued the probability at $85 \%$, tells there is no omitted variable in the model since the probability is greater than $5 \%$.

In the short run model among the total change in the rate of inflation only $22 \%$ is explained within the model by the joint force of explanatory variables as indicated by 0.22 value of $R 2$.

The variables which determine inflation in the short run are real interest rate and real effective exchange rate. Interest rate has negative relationship with the rate of inflation and its coefficient is interpreted as the value of interest rate changes by one unit the rate of inflation will changes by 0.62 units. Specifically inflation will decline as the rate of interest increases.

The other significance variable in this model in real effective exchange rate and it has a positive impact on inflation. As indicated by the coefficient of reer inflation will increases by one 0.84 units due to the upward movement of exchange rate by one unit. As shown in the above table the error correction model indicates that the error correction term is statistically significant and $1.78 \%$ of the disequilibrium created in the past will be corrected in the in the following year. The negative coefficient of the error correction term shows that at any period, if the inflation rate were above the normal condition, it will start falling in the next period and trickled down to the normal condition.

\section{Conclusion and Recommendation}

The econometric analysis based on the classical economic OLS estimation model gives the following results, which in turn support to the conclusion of this study. The result revealed that, the most important determinants of long run inflationary trend in Ethiopia are broad money supply, real interest rate and real effective rate. On the other hand gross domestic saving is statistically insignificant and does nothing in the process of affecting inflation in the long run.

Real effective exchange rate is one of the important variables in determining inflation both in the long run and short run and this is consistence hypothesis that currency devaluation affects inflation positively. Based on findings of this study, it is advisable to the national bank of Ethiopia to appreciate domestic currency to direct the foreign exchange market in the way that only those who aimed to add value to the real sector should be given attention. Fixing the exchange rate in line with trade partner countries is also one way of controlling the imported inflation through currency devaluation.

Real interest rate has also significant coefficient both in the short run and long run model of this study and it has negative relationship with the rate of inflation. The rate of interest has to be has to be decreased in the country to reduce the level of inflation.

The Ethiopian monetary base, which is broad cash in hand has some dispersion or different impact in determining inflation. It has significant impact within the long term but became statistically insignificant within the short run since monetary policy has higher outside lag and desires longer time to affect inflation after increasing money supply. So it's advisable to the policy makers to search out the correct balances whether money supply permanently determines rate of inflation or it's insignificance in both short run and future models.

\section{References}

[1] Alemayehu G (2011). The basic determinants of inflation in the case of least developed countries, working paper in African journal under IMF supervision, page no 45. 
[2] Beletelhem G (2012). Determinants inflation: the case of Ethiopia, thesis in the fulfillment of MSc degree from Addis Ababa University.

[3] Dejan, K (2007). Short Term Inflation Projections for Slovenia, Comparing Factor Models with AR and VAR models. journal of economics and sustainable development v.6.

[4] Demandor N Gujarati (2004). basic econometrics, $4^{\text {th }}$ edition, page no 325, Mc Grow Hill international, New York.

[5] Habtamu D (2000). The cause of low inflation in Ethiopia, M. A Thesis, Addis Ababa University, page no 10.

[6] Kibrom $\mathrm{T}$ (2008). The Sources of the Recent Inflationary Experience in Ethiopia, Addis Ababa University, Department of Economics, Unpublished MSc Thesis.

[7] Kenny A (2013). What determines inflation in Kazakhstan, $5^{\text {th }}$ edition, page no 345- 347.

[8] Kibritioglu K (2012). Recent inflationary trend in OPEC countries and its immediate determinants page no 89 .

[9] Mishkin F. J (1997). the determinants of inflation in Nigeria, IMF staff members, page no 24.
[10] MoFEC (2010). National Economic Accounts Directorate. Ministry of Finance and Economic Development, November 2010, Addis Ababa.

[11] Muche K (2007). Recent trend of inflation and its main determinants the case of Ethiopia. Working paper in economics. 14-16

[12] Case of Ethiopia. Working paper in Economics, No 347.

[13] Semmu G (2003). Why inflation is continuously rising in Ethiopia, The case of food price, Haromaya university M. A thesis.

[14] Sisay M (2008). Determinant of recent inflation on Ethiopia, Unity University, MA Thesis 34-45.

[15] Taddele F (2008). Forecasting model of Inflationary process in Ethiopia. Addis Ababa University, Department of Statistics, Unpublished M.sc Thesis.

[16] Yohannes A (2009). Inflation Dynamics and Food Prices in Agricultural Economy: The journal of economics and sustainable development. V.11 page 34 . 